\title{
Inactivation kinetics of horseradish peroxidase in organic solvents of different hydrophobicity at different water contents
}

\author{
Jorge Saraiva $^{1}$, Jorge C. Oliveira ${ }^{1 *}$, Susana Oliveira ${ }^{1} \&$ Marc Hendrickx $^{2}$ \\ 1 Escola Superior de Biotecnologia, Universidade Católica Portuguesa, R. Dr. António Bernardino de Almeida, 4200 \\ Porto, Portugal and \\ 2 Centre for Food Science and Technology, Faculty of Agriculture and Applied Biological Sciences, Katholieke \\ Universiteit Leuven, Kardinaal Mercierlaan 92, B3001 Heverlee, Belgium
}

\begin{abstract}
Summary The thermal stability of horseradish peroxidase suspensions was studied in three organic solvents of different hydrophobicity (dodecane, octane, and 1-octanol) at three different water contents (14.1, 55.3 and $256.2 \mathrm{mg}$ water $\mathrm{g}^{-1}$ dry protein). In these conditions, the enzyme is much more stable than in aqueous solutions (inactivation temperatures were in the range of $125-150^{\circ} \mathrm{C}$ ). The enzyme showed a similar stability when in the presence of organic solvents, compared to the enzyme in a solid matrix without organic solvents with the same water content. The inactivation kinetics was well described by assuming the existence of two iso-enzymes, both inactivating according to a first order model. The lowest value for the z-value of both fractions (around $15^{\circ} \mathrm{C}$ ) was obtained at the higher water content studied. The use of solvent and water content variables should be adequate to develop time-temperature integrators to monitor thermal processes at $100-140^{\circ} \mathrm{C}$.
\end{abstract}

Keywords Biocatalysis, enzyme thermal inactivation, time-temperature integrators, water activity.

\section{Introduction}

Important pioneering work on enzyme activity in organic suspensions was reported by Dastoli et al. (1966) for chymotrypsin. More recently, a variety of enzymes were found to be active as suspensions in several dried organic solvents (peroxidase - Kazandjian et al. (1986); subtilisin - Zaks \& Klibanov (1988a); polyphenol oxidase, alcohol oxidase and dehydrogenase - Zaks \& Klibanov (1988b)). This indicates that enzymatic catalysis in organic solvents may be of general occurrence, which leads to both practical applications as well as more fundamental studies in the field of biocatalysis.

The existing data show that in non-aqueous media, enzymes acquire remarkable stability

*Correspondent: Fax: ++351 2590351.

e-mail: jorge@esb.ucp.pt against temperature as well as new catalytic properties (Klibanov, 1986; Dordick, 1991). Perhaps the most interesting new properties are alteration of substrate/inhibitor specificity and ' $\mathrm{pH}$ - and ligand-induced memory' (Zaks \& Klibanov, 1985; Zaks \& Klibanov, 1988a; Mozhaev et al., 1991). These new properties, together with absence of liquid water in the reaction media, allow reactions to proceed that are normally not easily accomplished in aqueous environments (e.g. transesterifications and esterifications). Theoretically it should be possible to obtain intermediate products that rapidly hydrolyse in water (Klibanov, 1989).

One aspect of great importance for the industrial application of biocatalysis is protein heat stability. Completed studies are mainly related to denaturation studies (Barone et al., 1993; Battistel \& Bianchi, 1993) or confined to experiments at only one, or in few cases two, inactivation tem- 
peratures (Mozhaev et al., 1991; Zaks \& Klibanov, 1985) making comparisons very difficult. The activation energy of the inactivation process can vary quite considerably, causing the reaction rate constant to change differently in different environments. For instance the activation energy for inactivation of dried horseradish peroxidase changes with moisture content so that opposite conclusions concerning stability were made when results at $140^{\circ} \mathrm{C}$ were compared with results at $>146^{\circ} \mathrm{C}$, when the moisture contents were either 16.2 or $25.6 \%$ on a dry basis (Hendrickx et al., 1992).

A systematic study on the effect of organic solvents and water content on the stability of horseradish peroxidase is now reported. Inactivation was studied at three different water contents and in three organic solvents (dodecane, octane, and 1-octanol). An important practical application of this study is the development of enzyme-based time-temperature integrators (TTI), to monitor thermal processing in the range of conditions used for microbial sterilization. The requirements necessary for a TTI to be effective (Hayakawa, 1978), rely upon previous work on inactivation of dried peroxidase in absence of organic solvents, which indicated that the stability of this enzyme has to be decreased and the activation energy of the inactivation process increased (the z-value decreased) (Hendrickx et al., 1992). The possibility of using organic solvents for these two tasks is also evaluated in this work. The results obtained are also briefly compared to those reported by Hendrickx et al. (1992) for dried peroxidase in absence of organic solvents.

\section{Materials and methods}

\section{Lyophilization and equilibration}

Duplicate samples $(250 \mu \mathrm{L})$ of horseradish peroxidase (EC 1.11.1.7., RZ $=0.98$; Sigma, St. Louis, MO, USA) were lyophilized $\left(80 \mathrm{mgL}^{-1}\right.$ in distilled water) in crimp top vials (Chrompack, $0.8 \mathrm{~mL}$ ) before equilibration $\left(6\right.$ days at $4^{\circ} \mathrm{C}$ ) over saturated salt solutions of water activities $\left(\mathrm{a}_{\mathrm{w}}\right)$ of $0.11,0.43$, and 0.88 (Greenspan, 1977). The sorption isotherm for horseradish peroxidase was previously determined gravimetrically (Hendrickx et al., 1992) and the final content of water in the protein equilibrated at water activities $0.11,0.43$, and 0.88 at $4^{\circ} \mathrm{C}$ is, respectively, 14.1, 55.3, and 256.2 (mg water per $\mathrm{g}$ of dry protein).

\section{Organic solvent handling and addition}

The hydrophobicity of the organic solvents used decreases in the order dodecane $>$ octane $>1$ octanol, as indicated by their $\log P$, respectively, 6.6, 4.5, and 2.9. $P$ for a certain organic solvent is the partition coefficient of that solvent between water and octanol and is considered to be a measure of the hydrophobicity of the organic solvent (Laane et al., 1987). The organic solvents, bought from Aldrich Chemical Company Ltd., were removed from the bottles according to the handling instructions of the manufacturer. This step was very carefully carried out to avoid atmosphere contact. After the first use, and for an extra precaution, each bottle was kept in a closed vessel over phosphorous pentoxide.

On the 7th day of equilibration, the dried organic solvents $(350 \mu \mathrm{L})$ were added to the enzyme powder. The vials were tightly hand crimped as rapidly as possible and then subjected to $2 \mathrm{~min}$ of ultrasound treatment to form a fine suspension. The closed vials were kept at $4^{\circ} \mathrm{C}$ until the material was used for thermal inactivation experiments. The amount of water in the organic phase prior to addition to the enzyme powder was found to be below the detection limit of the Karl-Fischer titration, and consequently the results reported in this communication are analysed according to the total water content initially present in the solid-phase protein.

It should be noted that water may be divided between the solid phase and the organic phase and therefore the results may not reflect exactly the amount of water which is effectively bound to the enzyme.

Water is so immiscible with dodecane that for the volumes in question less than $2 \%$ of the water initially present in the enzyme would saturate the organic phase. For octane, according to the work of Gorman \& Dordick (1992) with comparable solvents, less than $1 \%$ of water bound to the enzyme after lyophilization would be stripped off by the solvent at $25^{\circ} \mathrm{C}$. However, for 1-octanol the above mentioned work indicated that strip- 
ping can be significant, in the order of $35 \%$ of the water initially bound to the enzyme.

One inactivation experiment was carried out in $\mathrm{N}, \mathrm{N}$-dimethylformamide (DMF), an hydrophilic organic solvent with a $\log P$ of -1.0 and the procedure was as follows: after cooling the enzyme suspension, cold phosphate buffer was added slowly, since its addition caused a temperature increase. An aliquot of this buffer-DMF mixture was used for peroxidase activity analysis in a glass cuvet, since this mixture deteriorated plastic cuvets.

\section{Thermal treatment}

The closed vials were transferred directly from $4^{\circ} \mathrm{C}$ to an oil bath at the desired and constant inactivation temperature and after predetermined time intervals quickly transferred to an ice bath. After cooling, the vials were opened, and phosphate buffer $(0.1 \mathrm{M}, \mathrm{pH} 7.0,375 \mu \mathrm{L})$ added to each. The two phases were then vigorously mixed and the contents transferred to a test tube with a conical bottom to facilitate phase separation. The tubes were held in ice until analysis for remaining activity, when samples were carefully withdrawn to avoid contamination of the organic phase.

Since the vials were very thin and heating times very large, the thermal lag effect was neglected.

\section{Activity analysis}

The peroxidase activity was measured according to the procedure suggested by Worthington (Worthington, 1978) using the methodology previously described by Hendrickx et al. (1992). The initial reaction rate was used to express the activity of the enzyme $\left(\Delta \mathrm{OD} \mathrm{min}^{-1}\right)$. The substrate solution was always freshly prepared.

\section{Data analysis}

In literature, the biphasic inactivation kinetics of soluble horseradish peroxidase has been analysed by the two-fraction model (Ling \& Lund, 1978). This model considers that there are two fractions of the enzyme (a heat-stable fraction and a heatlabile fraction), each with its own kinetic parameters, but inactivating independently and according to a first order decay. In the inactiva- tion experiments where biphasic behaviour was observed, this same model was used:

$$
\begin{aligned}
\frac{A}{A_{o}}=A_{o s} * \exp (-t & \left.* \frac{\operatorname{Ln}(10)}{D_{s}}\right)+ \\
& \left(1-A_{o s}\right) * \exp \left(-t * \frac{\operatorname{Ln}(10)}{D_{1}}\right)
\end{aligned}
$$

where $\mathrm{A}$ is the total residual activity of the enzyme $\left(\Delta \mathrm{OD} \mathrm{min}^{-1}\right), \mathrm{A}_{\mathrm{o}}$ is the total initial activity

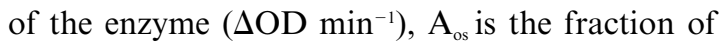
the heat stable activity of the enzyme, $\mathrm{D}$ is the decimal reduction time at temperature $\mathrm{T}(\mathrm{min}), \mathrm{t}$ is the heating time (min) and the subscripts $\mathrm{s}$ and 1 refer to the stable and labile fractions, respectively.

By definition, the D-value and the rate constant are related as follows:

$$
\mathrm{k}=\frac{\operatorname{Ln}(10)}{\mathrm{D}}
$$

Temperature dependence of the $\mathrm{D}$-value is represented with the z-value:

$$
\mathrm{D}=\mathrm{D}_{\mathrm{ref}} * 10^{\frac{\mathrm{T}_{\mathrm{sus}}-\mathrm{T}}{2}}
$$

where $\mathrm{T}$ is the temperature $\left({ }^{\circ} \mathrm{C}\right), \mathrm{z}$ is $\mathrm{z}$-value $\left({ }^{\circ} \mathrm{C}\right)$ and the subscript ref refers to a reference temperature.

The fitting of the experimental data to the kinetic models is conventionally carried out in two steps: first the unknown parameters, $D_{s}, D_{1}$, and $\mathrm{A}_{\mathrm{os}}$, at each temperature are estimated by fitting each experimental curve to eqn 1 using non-linear regression, and then the $\mathrm{z}$-values are obtained by fitting the individual $\mathrm{D}$-values to a linearized form of eqn 3. However, this procedure (known as two-step analysis) has some statistical drawbacks: the standard deviation is very large since the second regression is a regression of points already obtained by a regression (each with its error) and involving a small number of points (the number of individual experiments, each at one temperature, usually varies between 3 and 6, for literature data - Haralampu et al. (1985)). Alternatively, eqns 1 and 3 can be combined and a non-linear regression used to obtain directly the values for $\mathrm{A}_{\mathrm{os}}, \mathrm{D}_{\text {sref }}, \mathrm{D}_{\text {lref }}, \mathrm{z}_{\mathrm{s}}$ and $\mathrm{Z}_{\mathrm{l}}$, which is known as a one-step analysis. It should be noted that it is necessary to assume 
that the value of $\mathrm{A}_{\mathrm{os}}$ does not change with temperature. A two-step procedure might therefore be needed in a preliminary analysis to validate this assumption.

Linear and non-linear regression analysis (Stata 3.0 software) were used for all regressions and a reference temperature of $140^{\circ} \mathrm{C}$ was used for the one-step analysis.

\section{Results and discussion}

\section{Preliminary experiments}

The optimum conditions for peroxidase activity analysis were determined by Weng et al. (1987) and the same conditions were used in this work. Linearity between enzyme concentration and the initial reaction rate $\left(\Delta \mathrm{ODmin}^{-1}\right)$ for $\Delta \mathrm{ODmin}^{-1}$ values between 0.0 and 1.2 was previously reported (Hendrickx et al., 1992) and all activity measurements were in this range.

Lyophilization and equilibration above the different saturated salt solutions was found to have no significant effect on peroxidase activity (Hendrickx et al., 1992).

The effect of the organic solvents on peroxidase activity was studied for dodecane, octane and 1octanol at $4^{\circ} \mathrm{C}$ and water contents 14.1 , and $256.2 \mathrm{mg}$ water $\mathrm{g}^{-1}$ dry protein (corresponding to water activities of 0.11 and 0.88 ), for a period of 10 days. For dodecane there was a decrease of about 10 and $5 \%$ of peroxidase activity at water contents of 14.1 and $256.2 \mathrm{mg} \mathrm{g}^{-1}$ dry protein, respectively; for octane a decrease of about $10 \%$ for both water contents; and for octanol a $5 \%$ increase of peroxidase activity for both cases. These peroxidase activity variations were detected after $30 \mathrm{~min}$ contact, but peroxidase activity remained constant thereafter for the whole period. This indicates an immediate effect, probably because of the fast change of environment of the enzyme that may be caused by interfacial inactivation during vigorous mixing for enzyme recovery, rather than a progressive effect that would affect the thermal stability studies. Similar effects were reported by Burke et al. (1992) for disruption of the active centre structure of $\alpha$ chymotrypsin immediately after addition of organic solvents. In the case of DMF, no effect on peroxidase activity was found.

Since peroxidase has been known to regenerate after thermal inactivation in aqueous solution (Adams, 1978), partially inactivated samples were carefully re-analysed after $24 \mathrm{~h}$ storage at $4^{\circ} \mathrm{C}$. In all cases tested there was no indication of detectable regeneration of peroxidase activity.

\section{Inactivation experiments}

Table 1 shows the results obtained with the three solvents, using the one-step regression. The results of the two-step regression are only shown for 1-octanol, in Table 2. This is the case where the more significant difference between the two regression procedures was found and is sufficient to discuss the influence of the regression method. Although the z-values obtained with the two step method appear to be different, particularly for the lowest water content, there is a very high error in the two-step analysis (Table 2) even in the first
Table 1 Kinetic parameters obtained for inactivation of peroxidase in dodecane, octane and 1-octanol using the one-step analysis, and their $95 \%$ confidence interval.

\begin{tabular}{lllllll}
\hline Solvent & $\begin{array}{l}\mathbf{w} \\
\left(\mathbf{m g ~ g} \mathbf{~}^{-1}\right)\end{array}$ & $\begin{array}{l}\mathbf{A}_{\text {os }} \\
(\%)\end{array}$ & $\begin{array}{l}\mathbf{D}_{\mathbf{s}}^{140} \\
(\mathbf{m i n})\end{array}$ & $\begin{array}{l}\mathbf{D}_{1}^{140} \\
(\mathbf{m i n})\end{array}$ & $\begin{array}{l}\mathbf{z}_{\mathbf{s}} \\
\left({ }^{\circ} \mathbf{C}\right)\end{array}$ & $\begin{array}{l}\mathbf{z}_{\mathbf{l}} \\
\left({ }^{\circ} \mathbf{C}\right)\end{array}$ \\
\hline Dodecane & 14.1 & $36.8 \pm 3.5$ & $28.9 \pm 1.7$ & $2.5 \pm 0.7$ & $21.7 \pm 1.1$ & $20.3 \pm 4.5$ \\
& 55.3 & $31.2 \pm 3.7$ & $30.1 \pm 2.5$ & $3.2 \pm 0.7$ & $23.0 \pm 1.2$ & $34.9 \pm 12.0$ \\
& 256.2 & $27.0 \pm 4.4$ & $29.7 \pm 3.2$ & $2.6 \pm 0.7$ & $17.6 \pm 1.1$ & $14.2 \pm 2.9$ \\
Octane & 14.1 & 100 & $23.9 \pm 0.8$ & - & $24.0 \pm 1.4$ & - \\
& 55.3 & 100 & $24.2 \pm 0.6$ & - & $22.1 \pm 1.0$ & - \\
& 256.2 & $26.3 \pm 4.5$ & $23.2 \pm 3.1$ & $1.9 \pm 0.7$ & $16.9 \pm 1.0$ & $15.5 \pm 3.8$ \\
1-octanol & 14.1 & $23.9 \pm 7.5$ & $14.2 \pm 2.3$ & $3.1 \pm 0.8$ & $21.6 \pm 1.9$ & $23.5 \pm 5.5$ \\
& 55.3 & $18.4 \pm 3.6$ & $32.3 \pm 4.0$ & $5.4 \pm 1.2$ & $17.3 \pm 1.7$ & $29.8 \pm 9.3$ \\
& 256.2 & $34.2 \pm 6.1$ & $31.1 \pm 3.6$ & $5.6 \pm 1.7$ & $20.9 \pm 1.3$ & $27.7 \pm 10.1$ \\
\hline
\end{tabular}

$\mathrm{w}$ (water content) is expressed in dry basis: $\mathrm{mg}$ water $\mathrm{g}^{-1}$ dry protein. $A_{o s}$ is the fraction of heat stable iso-enzyme.

Subscript $s$ identifies the stable fraction and subscript I the labile fraction. 
Table 2 Kinetic parameters obtained for inactivation of peroxidase in 1-octanol using the two-step analysis, and their $95 \%$ confidence intervals.

\begin{tabular}{|c|c|c|c|c|c|c|}
\hline $\begin{array}{l}w \\
\left(\mathbf{m g ~ g}^{-1}\right)\end{array}$ & $\begin{array}{l}\mathrm{T} \\
\left({ }^{\circ} \mathrm{C}\right)\end{array}$ & $\begin{array}{l}A_{o s} \\
(\%)\end{array}$ & $\begin{array}{l}D_{s} \\
(\min )\end{array}$ & $\begin{array}{l}D_{1} \\
(\min )\end{array}$ & $\begin{array}{l}z_{s} \\
\left({ }^{\circ} \mathrm{C}\right)\end{array}$ & $\begin{array}{l}z_{1} \\
\left({ }^{\circ} \mathrm{C}\right)\end{array}$ \\
\hline \multirow[t]{4}{*}{14.1} & 125 & $37.4 \pm 18.5$ & $51.6 \pm 12.9$ & $10.0 \pm 6.1$ & & \\
\hline & 130 & $34.9 \pm 22.9$ & $35.3 \pm 11.4$ & $6.7 \pm 5.8$ & & \\
\hline & 135 & $21.8 \pm 10.0$ & $27.3 \pm 6.7$ & $4.8 \pm 1.6$ & 32.8 & 35.3 \\
\hline & 140 & $14.4 \pm 12.3$ & $17.5 \pm 8.8$ & $3.8 \pm 1.3$ & & \\
\hline \multirow[t]{4}{*}{55.3} & 125 & $16.0 \pm 5.4$ & $227.6 \pm 78.9$ & $17.7 \pm 4.8$ & & \\
\hline & 130 & $20.8 \pm 8.8$ & $109.0 \pm 35.0$ & $10.6 \pm 4.4$ & & \\
\hline & 135 & $26.1 \pm 5.4$ & $58.9 \pm 6.7$ & $7.1 \pm 1.9$ & 16.6 & 26.2 \\
\hline & 140 & $21.2 \pm 10.5$ & $27.5 \pm 7.1$ & $4.7 \pm 1.7$ & & \\
\hline \multirow[t]{4}{*}{256.2} & 125 & $25.7 \pm 5.0$ & $178.3 \pm 21.0$ & $21.1 \pm 5.5$ & & \\
\hline & 130 & $39.1 \pm 7.9$ & $88.5 \pm 9.4$ & $11.3 \pm 4.2$ & & \\
\hline & 135 & $46.4 \pm 14.3$ & $52.6 \pm 8.6$ & $8.2 \pm 5.2$ & 18.8 & 23.7 \\
\hline & 142.5 & $36.1 \pm 12.3$ & $20.2 \pm 3.6$ & $3.7 \pm 1.7$ & & \\
\hline
\end{tabular}

$\mathrm{w}$ (water content) is expressed in dry basis: $\mathrm{mg}$ water $\mathrm{g}^{-1}$ dry protein.

$A_{o s}$ is the fraction of heat stable iso-enzyme.

Subscript s identifies the stable fraction and subscript I the labile fraction. regression, visible as $A_{o s}$. This is caused by the relatively low number of points available in one single isothermal experiment, considering the number of kinetic parameters. By using a onestep regression with all data, the accuracy is greatly improved. This gives a clear example of the advantages of the one-step regression. Figure $1 \mathrm{a}$ and $\mathrm{b}$ show representative cases of inactivation with octane and octanol, respectively, both with $14.1 \mathrm{mg}$ water $\mathrm{g}^{-1}$ dry protein, showing the model fits with both regressions. The difference arising from a different $A_{o s}$ value is very visible $\left(\mathrm{A}_{\mathrm{os}}\right.$, in the semi-log graphs of Fig. $1 \mathrm{a}$ and $\mathrm{b}$, is given by the intercept of the straight line for high values of time).

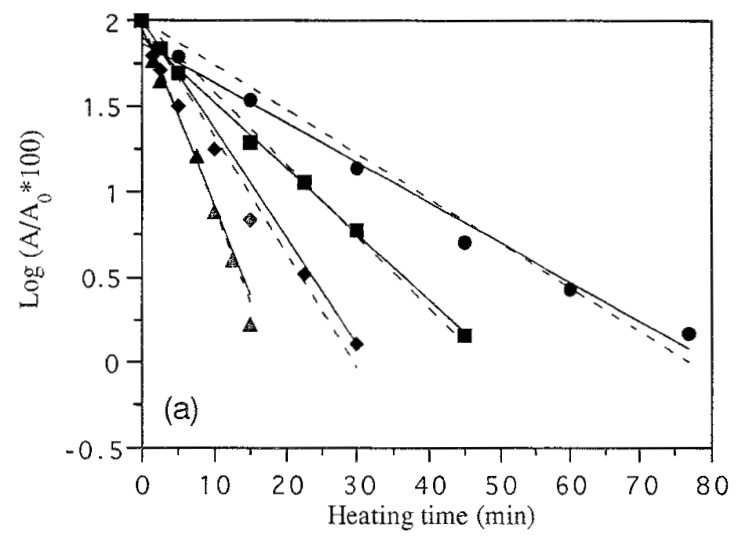

\section{Effect on the amount of stable fraction}

The $A_{o s}$ value obtained with the two-step analysis did not vary significantly with temperature, and therefore the one-step analysis using a constant $\mathrm{A}_{\mathrm{os}}$ is legitimate.

Analysing the effect of water content and solvent on $A_{o s}$ in Table 1, it can be concluded that at the highest water content the type of organic solvent did not affect the heat-stable fraction of the enzyme while for the other water contents each solvent lead to a different behaviour, with the limit being octane, where there was no heatlabile fraction (given the range of the D-values, it was considered that the stable fraction represent-

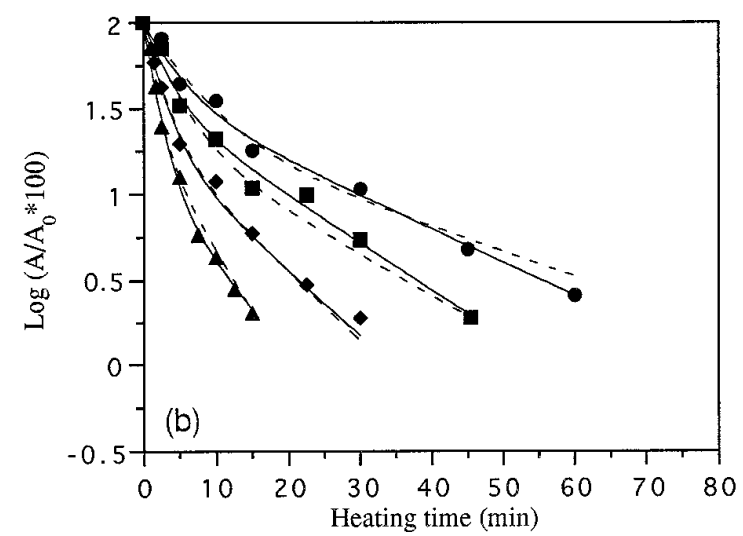

Figure 1 Heat inactivation kinetics of peroxidase at water content of $14.1 \mathrm{mg} \mathrm{g}^{-1}$ dry protein: (a) in octane at $135^{\circ} \mathrm{C}(\bullet)$, $140^{\circ} \mathrm{C}(\boldsymbol{\square}), 145^{\circ} \mathrm{C}(\bullet)$ and $150^{\circ} \mathrm{C}(\boldsymbol{\Delta})$ and (b) in octanol at $125^{\circ} \mathrm{C}(\bullet), 130^{\circ} \mathrm{C}(\boldsymbol{\nabla}), 135^{\circ} \mathrm{C}(\diamond)$ and $140^{\circ} \mathrm{C}(\boldsymbol{\Delta})$ and model curves using the one- $(----)$ and two-step (- - parameters. 
ed the total activity and consequently the $\mathrm{A}_{\mathrm{os}}$ value was $100 \%$ ). For dodecane and octane, the results at the two lowest water contents were not statistically different, while a difference existed for 1-octanol.

The first order kinetics observed for octane (at the two lowest water contents) was not an artefact because of peroxidase activity decrease after addition of the organic solvent (mentioned in the preliminary experiments), since it cannot account, by far, for the disappearance of one of the fractions. Moreover, this peroxidase activity decrease is the same for 14.1 and $256.2 \mathrm{mg}$ water $\mathrm{g}^{-1}$ dry protein, but the inactivation kinetics are different in the two cases. Similar changes from first order to biphasic kinetics were reported by De Cordt (1994) for $\alpha$-amylase, when the enzyme was inactivated in aqueous solution or immobilized. In these two cases, peroxidase inactivation exhibited a first order kinetics, as if it consisted of an homogeneous population. The explanation for this, may be because of the fact that, although the two-fraction model can describe reasonably well the experimental data, it is just a mathematical model and the existence of two fractions may not be the reality. This would be supported by the fact that the biphasic behaviour of other modified forms of peroxidase and other proteins can be described by other models - the nth-order model (Weng, 1991) and the series-type model (Clochard $\&$ Guern, 1973). In contrast with the two-fraction model, these two models suppose the existence of an homogeneous population of the native protein. The elucidation of the specific effect of octane observed needs a more fundamental understanding of the molecular mechanism of inactivation and work is currently under way to elucidate this particular aspect.

\section{Effect on the thermal stability (D-value at reference temperature)}

Table 1 also shows that for octane and dodecane the decimal reduction times for the stable fraction at the reference temperature were approximately independent of the water content, with a significantly higher value for the stable fraction in dodecane (around $30 \mathrm{~min}$ ) compared to octane (around $24 \mathrm{~min}$ ). Octanol provided a different situation, with the stable fraction similar at the highest water contents, but decreasing significantly at the lowest water content. The error in the parameters for the labile fraction is relatively large. This is natural, because this fraction inactivates fast, particularly at higher temperatures, and therefore the number of experimental points relevant to its description is comparatively small. Consequently, the results obtained for the labile fraction have poor statistical significance and are not analysed in detail.

\section{Effect on the temperature sensitivity (z-value)}

The z-value was not greatly influenced by the organic solvent used or water content. In absence of organic solvents (Hendrickx et al., 1992) there was an increase of the z-values with water activity $\left(\mathrm{a}_{\mathrm{w}}\right)$ for both fractions with a maximum close to 0.8 and then a significant decrease, with the highest $\mathrm{a}_{\mathrm{w}}$ leading to the lowest $\mathrm{z}$-value (around $17^{\circ} \mathrm{C}$ for the stable fraction and around $23^{\circ} \mathrm{C}$ for the labile fraction). It can be seen that the presence of organic solvents decreased the influence of water content on the z-values.

\section{Effect of increased water availability}

To further evaluate the effect of the organic solvent's hydrophobicity on the decimal reduction times, an inactivation experiment at $55.3 \mathrm{mg} \mathrm{g}^{-1}$ water content $\left(0.43 \mathrm{a}_{\mathrm{w}}\right)$ using DMF was carried out. This organic solvent caused a remarkable decrease in the stability: the D-values were 2 and $30 \mathrm{~min}$ for labile and stable fractions, respectively, at $80^{\circ} \mathrm{C}$. This result indicates that hydrophilic organic solvents can considerably decrease the stability of dried peroxidase, possibly because they allow for an increase in the amount of water accessible to the enzyme inactivation mechanism.

In order to analyse the effect of higher water concentrations, an experiment was carried out in octanol with $0.5 \% \mathrm{v} / \mathrm{v}$ water (about 100 times more water than in the other experiments), using enzyme previously equilibrated at $0.43 \mathrm{a}_{\mathrm{w}}$. D-values at $100^{\circ} \mathrm{C}$ of 9 and $77 \mathrm{~min}$ for the labile and stable fractions, respectively, were obtained, again showing the significant decrease in stability because of a larger availability of water molecules. 


\section{General interpretation of the results}

In all cases studied, horseradish peroxidase is much more stable than in aqueous solution (where inactivation is normally carried out at temperatures between 60 and $90^{\circ} \mathrm{C}-$ Weng et al. (1987)). In the organic solvents used the enzyme is slightly less stable than dried peroxidase inactivated in dry air. This high thermal resistance of dried enzymes in absence of organic solvents and in hydrophobic organic solvents has been reported for other enzymes (Multon \& Guilbot, 1975; Zaks \& Klibanov, 1985; Mozhaev et al., 1991). The high thermal stability of dried enzymes in air and in organic solvents is because of the absence of water. Since water is a reactant or a mediator of processes leading to irreversible thermal inactivation of enzymes and facilitates protein flexibility allowing thermo-unfolding (Volkin et al., 1991), its suppression from the reaction media results in more stable proteins.

To develop a TTI for the sterilization range of temperatures, hydrophilic organic solvents or high water concentrations, can be used to manipulate the stability by controlling the reaction rate constant. To decrease the z-value, other methods must be envisaged, because none of these factors are able to do this. Manipulation of the inactivation rate constant, using hydrophilic organic solvents or high water contents, can also help to adjust the stability of a certain batch of enzyme for a defined TTI use.

A final comment is given in relation to the fact that the amount of water effectively bound to the enzyme is not known and that the results were analysed in terms of the total amount of water bound to the enzyme before the solvent addition. It was stated earlier that for dodecane and octane stripping of water by the solvent is not expected to be significant, while for 1-octanol it may be relevant. However, it is curious to note that the effect of water content with 1-octanol was low, just like in dodecane where the water stripping effect is not relevant.

\section{Conclusions}

Dried horseradish peroxidase was found to be much more stable to inactivation in organic solvents than in aqueous solutions. The organic sol- vents caused a slight decrease on the stability in relation to inactivation in their absence and little effect on z-values, particularly decreasing the influence of water content on the z-value of the stable fraction. Hydrophilic organic solvents and high water concentrations remarkably decreased the stability of dried peroxidase (the inactivation temperatures change from 125 to $145^{\circ} \mathrm{C}$ to 80 and $100^{\circ} \mathrm{C}$, respectively). To develop a timetemperature integrator to monitor thermal processes at $100-140^{\circ} \mathrm{C}$, the use of these two factors is adequate to change the stability of the enzyme but not the z-value. Octane at low water contents changed the profile kinetics from biphasic to first order.

\section{Acknowledgements}

The authors would like to acknowledge the Commission of the European Communities, AAIR programme (AIR1-CT92-0746), for financial support.

J. Saraiva gratefully acknowledges financial support from the Portuguese Junta Nacional de Investigação Científica e Tecnológica (JNICT). The authors would also like to acknowledge Fiona M. Berry for her help in carrying out part of the experimental work reported in this communication.

\section{References}

Adams, J.B. (1978). The inactivation and regeneration of peroxidase in relation to the high temperature-short time processing of vegetables. Journal of Food Technology, 13, 281-297.

Barone, G., Del Vecchio, P., Fessas, D., Giancola, C., Graziano, G. \& Riccio, A. (1993). In: Stability and Stabilization of Enzymes (edited by W. J. J. van den Tweel, A. Harder and R. M. Buitelaar). Pp. 37-44. Elsevier Science Publishers Ltd, Chister, UK.

Battistel, E. \& Bianchi, D. (1993). Influence of the solvent properties on protein stability in organic media. In: Stability and Stabilization of Enzymes (edited by W. J. J. van den Tweel, A. Harder and R. M. Buitelaar). Pp. 13-20. Elsevier Science Publishers Ltd, Chister, UK.

Burke, P.A., Griffin, R.G. \& Klibanov, A.M. (1992). Solid-state assessment of enzyme active center structure under nonaqueous conditions. Journal of Biological Chemistry, 267 (28), 20057-20064.

Clochard, A. \& Guern, J. (1973). Destruction thermique de l' activite peroxidasique. Interpretation des courbes experimentales. Revue Generale du Froid, 8, 860-870. 
Dastoli, F.R., Musto, N.A. \& Price, S. (1966). Reactivity of active sites of chymotrypsin suspended in an organic medium. Archives of Biochemistry and Biophysics, 115, 44-47.

De Cordt, S. (1994). Feasibility of development of proteinbased time-temperature-integrators for heat process evaluation. PhD thesis, Faculty of Agricultural Sciences, Katholieke Universiteit, Leuven.

Dordick, J.S. (1991). Principles and applications of nonaqueous enzymology. In Applied Biocatalysis, Vol. 1 (edited by H. W. Blanch and D. S. Clark). Pp. 1-51. New York: Marcel Dekker, Inc.

Gorman, L.A.S. \& Dordick, J.S. (1992). Organic solvents strip water off enzymes. Biotechnology and

Bioengineering, 39, 392.

Greenspan, L. (1977). Humidity fixed points of binary saturated aqueous solutions. Journal of the Research of the National Bureau of Standards - A. Physics and Chemistry, 81 (A), 89-96.

Haralampu, S.G., Saguy, I. \& Karel, M. (1985). Estimation of Arrhenius model parameters using three least squares methods. Journal of Food Processing and Preservation, 9, 129-143.

Hayakawa, K.I. (1978). A critical review of mathematical procedures for determining proper heat sterilization process. Food Technology, 3, 59.

Hendrickx, M., Saraiva, J., Lyssens, J., Oliveira, J. \& Tobback, P. (1992). The influence of water activity on thermal stability of horseradish peroxidase. International Journal of Food Science and Technology, 27, 33-40.

Kazandjian, R.Z., Dordick, J.S. \& Klibanov, A.M (1986). Enzymatic analyses in organic solvents. Biotechnology and Bioengineering, 28, 417-421.

Klibanov, A.M. (1986). Enzymes that work in organic solvents. Chemtec, 39, 354-359.

Klibanov, A.M. (1989). Enzymatic catalysis in anhydrous organic solvents. Trends in Biotechnology, 14, 141-144.
Laane, C., Boeren, S., Vos, K. \& Veeger, C. (1987). Rules for optimization of biocatalysis in organic solvents. Biotechnology and Bioengineering, 30, 81-87.

Ling, A.C. \& Lund, D.B. (1978). Determinating kinetic parameters for thermal inactivation of heat resistant and heat labile isozymes from thermal destruction curves. Journal of Food Science, 43, 1307-1310.

Mozhaev, V.V., Poltevsky, K.G., Slepnev, V.I., Badun, G.A. \& Levashov, A.V. (1991). Homogeneous solutions of hydrophilic enzymes in nonpolar organic solvents. New systems for fundamental studies and biocatalytic transformations. Febs Letters, 292 (1), 159-161.

Multon, J.L. \& Guilbot, A. (1975). Water activity to the thermal inactivation of enzymatic proteins. In: Water Relation of Foods (edited by R. B. Duckworth). Pp. 379-396. London: Academic Press Inc.

Volkin, D.B., Staubli, A., Langer, R. \& Klibanov, A.M. (1991). Enzyme thermoinactivation in anhydrous organic solvents. Biotechnology and Bioengineering, 37, 843-853.

Weng, Z.J. (1991). A time-temperature-integrator for thermal processing of foods: a case study on immobilized peroxidase. $\mathrm{PhD}$ thesis, Faculty of Agricultural Sciences, Katholieke Universiteit, Leuven.

Weng, Z.J., Hendrickx, M., Maesmans, G. \& Tobback, P. (1987). Thermostability of soluble and immobilised peroxidase. Journal of Food Science, 56, 574-578.

Worthington Biochemical Corporation (1978). Enzymes and related biochemicals. Pp. 145-146. Bedford: Millipore Corporation.

Zaks, A. \& Klibanov, A.M. (1985). Enzyme-catalysed processes in organic solvents. Proceedings of National Academy of Sciences (USA), 82, 3192-3196.

Zaks, A. \& Klibanov, A.M. (1988a). Enzymatic catalysis in nonaqueous solvents. Journal of Biological Chemistry, 263, 3194-3201.

Zaks, A. \& Klibanov, A.M. (1988b). The effect of water on enzyme action in organic media. Journal of Biological Chemistry, 263, 8017-8021.

Received 28 February 1995, revised and accepted 10 May 1996 